[Article]

\title{
一步湿化学法合成超细金纳米线
}

\author{
徐海英 ${ }^{1,2}$ 阚彩侠 ${ }^{1, *}$ 王长顺 ${ }^{1}$ 倪 媛 ${ }^{1}$ 刘津升 ${ }^{1}$ 徐 伟 ${ }^{1}$ 柯军华 ${ }^{1}$ \\ ( 1 南京航空航天大学理学院应用物理系, 南京 211106; 2 2 南京工程学院数理部, 南京 211167)
}

\begin{abstract}
摘要: 以氯金酸 $\left(\mathrm{HAuCl}_{4}\right)$ 为前驱物, 油胺同时作为溶剂、表面稳定剂和还原剂, 通过简单的一步湿化学法合成 超细金纳米线. 制备出的超细金纳米线不仅产量高、纯度高, 而且纵横比大, 纳米线平均直径 $2 \mathrm{~nm}$, 长度可达 数十微米. 如果添加另一种还原剂油酸并调节油胺和油酸的体积比为 $1: 1$, 将生成直径为 $~ 9 \mathrm{~nm}$ 的金纳米线. 通 过改变反应温度和还原剂用量, 对该种超细金纳米结构的生长机制进行阐述说明: 以油胺为模板, 在油胺和一 价金卤化物( $\mathrm{AuCl}$ )亲金键合形成的一维聚合链作用下, 被还原的金原子附着在已成核颗粒表面, 一维地生长成 超细金纳米线.
\end{abstract}

关键词: 准一维; 超细; 金纳米线; 湿化学法; 生长机制 中图分类号: 0648

\section{Ultrafine Au Nanowires Synthesized via One-Step Wet Chemical Method}

\author{
XU Hai-Ying ${ }^{1,2} \quad$ KAN Cai-Xia ${ }^{1, *} \quad$ WANG Chang-Shun ${ }^{1} \quad$ NI Yuan ${ }^{1}$ \\ LIU Jin-Sheng ${ }^{1} \quad$ XU Wei ${ }^{1} \quad$ KE Jun-Hua ${ }^{1}$
}

('Department of Applied Physics, College of Science, Nanjing University of Aeronautics and Astronautics, Nanjing 211106 , P. R. China; ${ }^{2}$ Department of Mathematics and Physics, Nanjing Institute of Technology, Nanjing 211167, P. R. China)

\begin{abstract}
Ultrafine Au nanowires (AuNWs) were synthesized in high yields by a one-step wet chemical method using oleylamine as the solvent, surfactant, and reductant. The obtained AuNWs were of high purity and had a high aspect ratio, with diameters of $\sim 2 \mathrm{~nm}$ and lengths of tens of micrometers. AuNWs of diameter $\sim 9 \mathrm{~nm}$ were also obtained in the presence of oleic acid, at an oleic acid:oleylamine volume ratio of 1:1. The formation of AuNWs was studied by changing the reaction temperature and the volume of oleylamine. It is proposed that the growth mechanism of the Au nanostructures involves strong aurophilic interactions from oleylamine-AuCl complexes; the reduced $\mathrm{Au}$ atoms agglomerate and attach to preformed particles, and the oleylamine molecular layer acts as a soft template, leading to one-dimensional growth of Au atoms into AuNWs.
\end{abstract}

Key Words: Quasi-one-dimension; Ultrafine; Au nanowire; Wet chemical method; Growth mechanism

\section{Introduction}

One-dimensional (1D) metallic nanostructures have continuously drawn significant research attention in recent years due to their unique electrical, optical, mechanical properties and their potential applications. ${ }^{1-11}$ For the face-centered cubic (fcc) structured noble metals, $\mathrm{Au}$ and $\mathrm{Ag}$ have very close lattice constants (0.4078 and $0.4086 \mathrm{~nm}$, respectively). However, researches on $\mathrm{Au}$ and $\mathrm{Ag}$ nanostructures show that their morphologies vary a lot through the same synthesis method. For example, in the same polyol process (with the same reaction temperature, solvent, and surfactant),

Received: January 19, 2015; Revised: March 30, 2015; Published on Web: April 1, 2015.

"Corresponding author. Email: cxkan@nuaa.edu.cn; Tel: +86-25-52113852.

The project was supported by the National Natural Science Foundation of China (11274173), Fundamental Research Funds for the Central Universities, China (NZ2015101, NJ20140005), Funding of Jiangsu Innovation Program for Graduate Education, China (KYZZ_0091), and Qing Lan Project of Jiangsu Province, China. 国家自然科学基金(11274173), 中央高校基本科研专项资金(NZ2015101, NJ20140005), 江苏省研究生培养创新工程(KYZZ_0091)及江苏省青 蓝工程资助项目 
large size of Au nanoplates (micrometers in lateral size) ${ }^{12}$ and long $\mathrm{Ag}$ nanowires (NWs, micrometers in length) ${ }^{13}$ are formed, respectively from their precursors. If water is used as solvent, small sized $\mathrm{Au}$ nanorods ${ }^{14,15}$ and $\mathrm{Ag}$ nanoplates ${ }^{16}$ will be formed. Therefore, the synthesis of long AuNWs and large sized Ag nanoplates is still a challenging topic.

Quasi-one-dimensional Au nanostructures have been synthesized through anion exchange resin, template-assisted electrochemical deposition. ${ }^{17-24}$ Ultrafine Au nanostructures have caused extensive attention, ${ }^{25-27}$ since chemical technology was applied to synthesize successfully ultrafine AuNWs by Yang et al. ${ }^{28}$ For special studies, electron-beam irradiation and suspension methods are only ever proposed for the fabrication of AuNWs by gentle contact of $\mathrm{Au}$ film or tip based on an electronic microscope under ultrahigh vacuum conditions. ${ }^{29,30}$ These techniques mainly resulted in the production of thick ( $>10 \mathrm{~nm}$ in diameter) or polycrystalline AuNWs, and even procedures are rather complicated. In many reports, the production of single-crystalline AuNWs required intermediate step or a long reaction time. ${ }^{5,30,31}$ There thus need to develop a simple method to produce high-quality AuNWs.

Studies have predicted that thin AuNWs, especially with sub-10 $\mathrm{nm}$ in diameter, have good electrical conductivity and are promising candidates for future molecular connections of the nanoelectronic aspects ${ }^{32-35}$ as well as active components in nanoscale electric and mechanical devices, owing to their excellent electrical and mechanical proterties. ${ }^{36-38}$ Herein, we report a simple wet chemical method for the production of high-quality ultrafine AuNWs. With the improvement to chemical process, ultrafine AuNWs can be obtained with $\sim 2 \mathrm{~nm}$ in diameter and tens of micrometer in length through chemical reaction between chloroauric acid $\left(\mathrm{HAuCl}_{4}\right)$ and oleylamine, in which oleylamine is used as the reducing agent and surfactant. The diameters of AuNWs can be tuned by changing the volume ratio of oleylamine to oleic acid.

\section{Experimental}

\subsection{Material}

The chemicals including oleylamine $\left(\mathrm{C}_{18} \mathrm{H}_{37} \mathrm{~N}, 40.0 \%\right)$, oleic acid $\left(\mathrm{C}_{18} \mathrm{H}_{34} \mathrm{O}_{2}, 99.0 \%\right)$, hexane $\left(\mathrm{CH}_{3}\left(\mathrm{CH}_{2}\right)_{4} \mathrm{CH}_{3}, 86.18 \%\right)$, and tetrachloroaurate $\left(\mathrm{HAuCl}_{4} \cdot 4 \mathrm{H}_{2} \mathrm{O}, 99.9 \%\right)$ were purchased from Shanghai Chemical Reagent Co. Ltd. Acetone $\left(\mathrm{CH}_{3} \mathrm{COCH}_{3}\right.$, $\geqslant 99.5 \%)$ and alcohol $\left(\mathrm{CH}_{3} \mathrm{CH}_{2} \mathrm{OH}, \geqslant 99.7 \%\right)$ were purchased from Sinopharm Chemical Reagent Co. Ltd. All the chemical reagents used were of analytical purity (purity level: AR) and were used without further purification.

\subsection{Synthesis of ultrafine AuNWs}

In a typical synthesis, $0.1 \mathrm{~g} \mathrm{HAuCl}_{4}$ was mixed with $1 \mathrm{~mL}$ oleylamine in $1 \mathrm{~mL}$ hexane, the mixture was injected into $9 \mathrm{~mL}$ oleylamine at $85{ }^{\circ} \mathrm{C}$ under vigorous magnetic stirring. In the process, hexane was evaporated under nitrogen atmosphere. $\mathrm{HAuCl}_{4}$ (orange color) reacted with oleylamine and formed organic halogen compound $\mathrm{AuCl}$ (colorless). The color changes of the mixture were shown in Fig.1(A, B). Then magnetic stirring was stopped after $10 \mathrm{~min}$ and the reaction process was kept at $85^{\circ} \mathrm{C}$ for $5 \mathrm{~h}$ until the color gradually changed to dark red (Fig.1C). After cooling the solution to room temperature, the colloid was dispersed in a mixed solution (acetone and ethanol with volume ratio of 1:3), and an obvious flocculent agglomeration was formed, as shown in Fig.1D. At last the agglomeration was redispersed in hexane for several hours (see Fig.1E), the dissolved product was separated several times with hexane to remove the excess oleylamine (see Fig.1F), and ultrasonication is required to dissipate the product in hexane (see Fig.1G) for further investigation.

\subsection{Characterization}

The samples were washed and deposited on a carbon-coated copper grid and dried under ambient condition for further measurements. Transmission electron microscope (TEM) and highresolution transmission electron microscope (HRTEM) images were obtained using JEOL-100CX and JEOL-2011 microscope, respectively.

\section{Results and discussion}

Fig.2(A, B) are TEM images of the product. From the morphologies we can see that the product consists of uniform and continuous AuNWs, together with a small number of large-sized AuNWs and nanoparticles. Most of the AuNWs are ultrafine with $\sim 2 \mathrm{~nm}$ in diameter and several micrometers in length. And these ultrafine AuNWs are flexible on TEM grid. Inset in Fig.2B clearly indicates that the nanowires are easily looped or bent on the grid edge.

The diameter of the AuNWs is likely to be further tuned by controlling solvent combination during the synthesis. AuNWs with $\sim 2 \mathrm{~nm}$ in diameter can be synthesized when only oleylamine is used as the solvent, and whereas AuNWs with $\sim 9 \mathrm{~nm}$ in diameter are obtained from a mixture solvent of $5 \mathrm{~mL}$ oleylamine and $5 \mathrm{~mL}$ oleic acid. Fig.2C is the HRTEM image of two individual AuNWs with $\sim 9 \mathrm{~nm}$ in diameter, which are synthesized by adding oleic acid replacing part of oleylamine as another reductant. Obviously, the diameter of AuNWs becomes significantly larger. The using of oleylamine, in other word, is better than

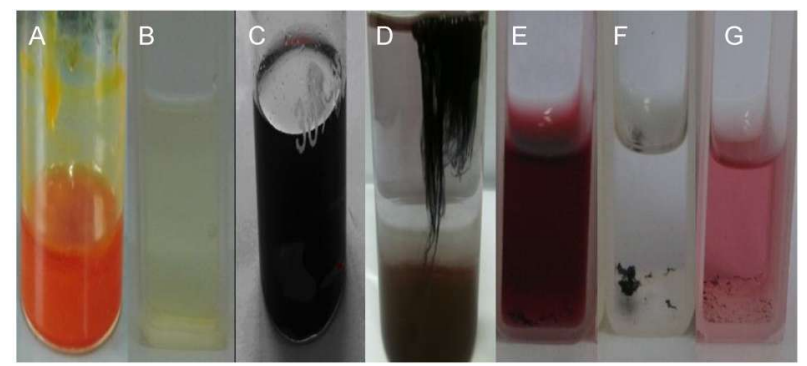

Fig.1 Photographs of the reaction system and products in separation process

(A) before, (B) during, and (C) after $\mathrm{HAuCl}_{4}$-oleylamine reaction; (D) the formed flocculent agglomeration when sample (C) dispersed in the mixture of acetone and ethonal, (E) the sediment of (D) dispersed in hexane, and the sediment of (E) before (F) and after (G) ultrasonication 

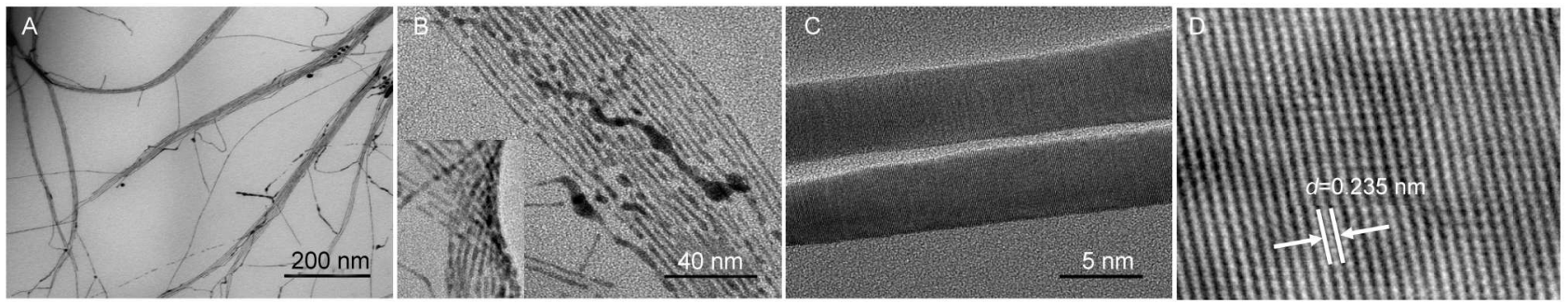

Fig.2 TEM and HRTEM images of ultrafine AuNWs

(A, B) TEM and HRTEM images of $2 \mathrm{~nm}$ ultrafine AuNWs, (C) HRTEM image of $9 \mathrm{~nm}$ ultrafine AuNWs, (D) inverse fast Fourier transform of the single crystalline part

oleic acid in the synthesis process. From Fig.2C, we can see that most of the AuNWs are single crystalline, and layer fault is also observed. Fig.2D is the HRTEM image of the single crystalline part of Fig.2C. It shows that single crystalline AuNWs grow along $<111>$ direction, the ordered crystal fringes perpendicular to $<111>$ direction with relatively smooth surface. The inter-fringe distance is measured to be $0.235 \mathrm{~nm}$ (Fig.2D), which is corresponding to (111) lattice spacing $(0.23 \mathrm{~nm})$ of the fcc Au crystal.

These synthesized AuNWs tend to form large bundles and selfassemble into densely packed bundles. Most of the observed ultrafine AuNWs are found to be self-assemblied with $\sim 2 \mathrm{~nm}$ distance because of the surface coverage of oleylamine linker between two adjacent nanowires. ${ }^{39}$ As described in the experiment, the flocculent agglomeration should be the packed network of AuNWs dissolved in hexane. In addition, it can be seen that the ultrafine AuNWs are easily to be melted or fractured by the electron beam irradiation for a long time under TEM measurement, as indicated by Fig.2(A, B).

In the procedure, the solvent oleylamine serves both as the reducing agent and soft template for stabilizing ultrafine AuNWs by forming $1 \mathrm{D}$ polymeric chain, ${ }^{31,40}$ on which there is a strong aurophilic interaction from the oleylamine- $\mathrm{AuCl}$ complexes. As can be seen in Fig.3, the salt precursor $\left(\mathrm{Au}^{3+}\right)$ is partly reduced at the beginning of the reaction and small gold clusters $\left(\mathrm{Au}^{+}\right)$are formed sequentially. Then, crystals nucleate from the continuous reduction of $\mathrm{Au}^{+}$inside the chain-like structure of oleyamine- $\mathrm{AuCl}$ complexes. Because these crystals have different surface energies on different facets, the density of oleylamine adsorbed on different surfaces varies, which directs the anistropic growth along the direction with lower packing density into ultrafine AuNWs. Inevitably, the continuous nucleation will form nanoparticle and thicker nanowire when higher gold concentrations are provided. ${ }^{31}$ Aurophilic bond of oleylamine-AuCl complexes plays a critical role in forming of ultrafine AuNWs. Schematic illustration for the formation of the ultrafine AuNW template shows that the strong interactions between amine molecules adsorbed on AuNWs, which directs the 1D development of the ultrafine AuNWs.

In order to further study the aurophilic bonding-assisted growth mechanism of AuNWs, we investigated the influences of reaction temperature and molar ratio of the reaction system on morphologies of Au nanostructures. The experiment is carried out at different temperatures $\left(70,80,85,90^{\circ} \mathrm{C}\right)$, and the morphologies of $\mathrm{Au}$ nanostructures are shown in Fig.4. Only Au nanoparticles with $\sim 12 \mathrm{~nm}$ in diameter are obtained at $70{ }^{\circ} \mathrm{C}$, as indicated in Fig.4A. HRTEM image (inset of Fig.4A) shows the five-fold twinned structure of the nanoparticle, which is the common and stable structure of fcc metal nanocrystal. It can be seen from the Fig.4B, nanowires alongside spheroidal nanoparticles appear in the product when the temperature is $80^{\circ} \mathrm{C}$. Comparatively, the diameter of nanowires is about equal to the size of the nanoparticles. When the temperature increases to $85^{\circ} \mathrm{C}$ (Fig.4C), ultrafine AuNWs ( $\sim 2 \mathrm{~nm}$ in diameter) with high quality and high purity were formed, compared to Fig.4B. However, the ultrafine AuNWs are usually assembled in bundles possibly due to the strong interaction between amine molecules adsorbed on the surface of AuNWs and the evaporation of solvent in the preparation of TEM sample. The product, obviously, is dominated by many $\mathrm{Au}$ nanoparticles and short nanowires ( $\sim 200 \mathrm{~nm}$ in length) together with a few of ultrafine AuNWs when the temperature continues up to $90{ }^{\circ} \mathrm{C}$. These results indicate that $80-85^{\circ} \mathrm{C}$ more or less is suitable for the growth of the nanowires, and considerably, $85^{\circ} \mathrm{C}$ is the optimal temperature to produce ultrafine AuNWs with the highest yield. If the temperature is higher than $100{ }^{\circ} \mathrm{C}$, only $\mathrm{Au}$ nanoparticles are obtained, possibly due to the thermal degradation which makes that AuNWs cannot keep their shapes steady. ${ }^{27}$

In short, the observed variations might be related to the state of $\mathrm{Au}$. The monovalent $\mathrm{Au}$ ions are gradually reduced to form a small amount of $\mathrm{Au}$ particles at the beginning and then slowly grow up to large and uniform particles. With increasing the reaction temperature, the nanoparticles will become smaller because of reconstruction and Ostwald ripening phenomenon, and AuNWs

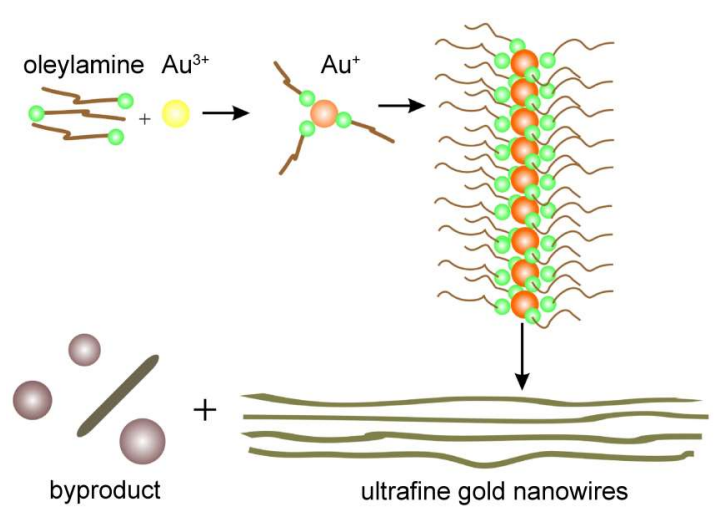

Fig.3 Schematic illustration for the formation of the ultrafine AuNWs 

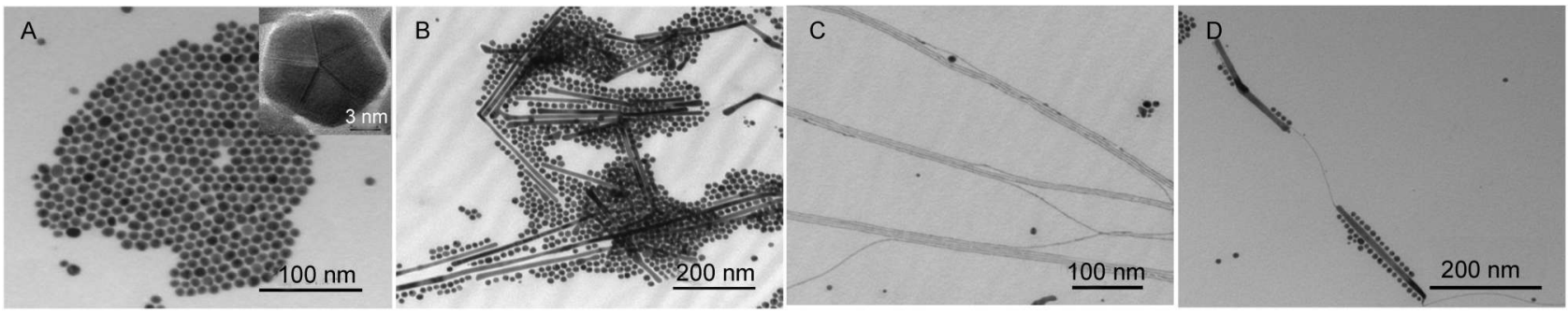

Fig.4 TEM images of products synthesized at different reaction temperatures (A) $70^{\circ} \mathrm{C}$, (B) $80^{\circ} \mathrm{C}$, (C) $85^{\circ} \mathrm{C}$, (D) $90^{\circ} \mathrm{C}$
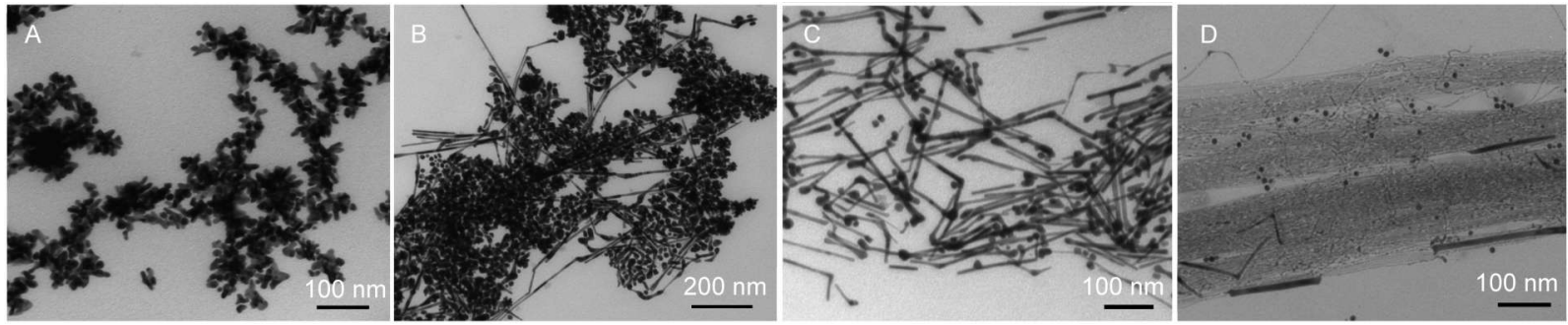

Fig.5 TEM images of products synthesized by changing the oleylamine volume

(A) $7 \mathrm{~mL}$, (B) $8 \mathrm{~mL}$, (C) $9 \mathrm{~mL}$, (D) $10 \mathrm{~mL}$

will be produced in the $1 \mathrm{D}$ polymeric template. ${ }^{40}$

Fig.5(A-D) are TEM images of synthesized product by changing the volume of oleylamine $(7-10 \mathrm{~mL})$ at $85{ }^{\circ} \mathrm{C}$ with other conditions unchanged. Fig.5A is the morphology of the product when $7 \mathrm{~mL}$ oleylamine is applied. It can be seen that branched $\mathrm{Au}$ nanostructures are formed under this condition, and no nanoparticles and nanowires can be observed. It is quite possible that the short chain of oleylamine combined with the reduced $\mathrm{Au}$ atoms from the oleylamine- $\mathrm{AuCl}$ complex and self-assembled into discontinuous chain- like structures. Then the nanoparticles aggregated into the branched nanostructure. With an increase of the volume of oleylamine, more oleylamine molecules coated on the surface of $\mathrm{Au}$, and the reduction of the chain-like structure formed the longer soft template, resulting in the formation of continuous chains. Because of atomic diffusion, aggregation, and recombination, the branched nanostructures began to grow into nanostructures such as nanotrees, long nanorods and nanowires, as shown in Fig. 5B.

When the volume of oleylamine is $8 \mathrm{~mL}$, it indicates that a high yield of Au long nanorods is formed. These Au long nanorods are thin, continuous, with a diameter of $\sim 5 \mathrm{~nm}$ and the length up to several hundreds nanometers (see Fig.4C). Nano- shaped tips (enlarged head-shaped/tadpole-shaped) are observed at the end of these nanorods. The generated nanorods by this process are generally much thinner than the head of the rods. There is no obvious decrease in the size of the head of the rods, which roughly retains their original spherical shape. ${ }^{41,42}$ When the oleylamine achieves a certain volume, the product is dominated by ultrafine AuNWs with diameter of $\sim 2 \mathrm{~nm}$ and the length up to several micrometers. These ultrafine AuNWs are uniform, high yield and self-assembly in bundles (see Fig.4D).

The above results, for the growth mechanism, indicate that the obtained products are confined by the chain-like template of the oleylamine- $\mathrm{AuCl}$ complex, as schematically illustrated by Fig.3. And the molar ratio of the oleylamine and $\mathrm{HAuCl}_{4}$ is also critical for the formation of ultrafine AuNWs. It can be understood that long hydrophobic chains with amino groups combine strongly with $\mathrm{Au}$, finally leading to the formation of ultrafine AuNWs. Oleylamine also plays a role of a surfactant, which provides a soft template for the oriented combination and recombination of $\mathrm{Au}$ particles, elongating the nanowires. The greater the volume of oleylamine in a certain range, the longer the tail chain, the higher the aspect ratio of nanowires.

\section{Conclusions and outlook}

This paper presents a simple synthesis of ultrafine AuNWs in an oil-bath at $85{ }^{\circ} \mathrm{C}$ for $5 \mathrm{~h}$ by reduction of $\mathrm{HAuCl}_{4}$ in oleylamine. The ultrafine AuNWs are high yield, high aspect ratio with diameter of $\sim 2 \mathrm{~nm}$. The as-synthesized ultrafine AuNWs could easily self-assemble into closely packed bundles possibly due to the strong interaction of the adsorbed amine on the surface of AuNWs, as well as the evaporation of solvent in the preparation of TEM sample. With adjusting the reaction temperature and the volume of the oleylamine, various shapes of $\mathrm{Au}$ nanostructures were formed by reconstruction from $\mathrm{Au}$ atoms or their agglomeration. In this method, oleylamine has multifunctional roles as the solvent, surfactant, and reductant. The surfactant induces anisotropic growth by adsorbing on the specific Au crystalline surface. The growth mechanism of using oleylamine as the soft template has been utilized to explain the formation of nanowires. This work is important for both fundamental study of their quantum properties and applications including sensors, waveguide, transparent conductive electrode, and nano-connector in electronic devices. 


\section{References}

(1) Xia, Y. N.; Xiong, Y. J.; Lim, B.; Skrabalak, S. E. Angew. Chem. Int. Edit. 2009, 48, 60. doi: 10.1002/anie.200802248

(2) Cui, Y.; Wei, Q. Q.; Park, H. K.; Lieber, C. M. Science 2001, 293, 1289. doi: 10.1126/science. 1062711

(3) Hu, S.; Wang, X. Chem. Soc. Rev. 2013, 42, 5577. doi: 10.1039/ c3es00006k

(4) Wiley, B.; Sun, Y. G.; Xia, Y. N. Accounts Chem. Res. 2007, 40, 1067. doi: 10.1021/ar7000974

(5) Halder, A.; Ravishankar, N. Adv. Mater. 2007, 19, 1854.

(6) Hu, Y.; Lu, L. H.; Liu, J. H.; Chen, W. J. Mater. Chem. 2012, 22, 11994. doi: 10.1039/c2jm31483e

(7) Li, C. C.; Cai, W. P.; Kan, C. X.; Zhang, L. D. Mater. Lett. 2004, 58, 196. doi: 10.1016/S0167-577X(03)00444-0

(8) Lacroix, L. M.; Arenal, R.; Viau, G. J. Am. Chem. Soc. 2014, 136, 13075. doi: 10.1021/ja507728j

(9) Takahata, R.; Yamazoe, S.; Koyasu, K.; Tsukuda, T. J. Am Chem. Soc. 2014, 136, 8489. doi: 10.1021/ja503558c

(10) Kempa, T. J.; Kim, S. K.; Day, R. W.; Park, H. G.; Nocera, D. G.; Lieber, C. M. J. Am. Chem. Soc. 2013, 135, 18354. doi: 10.1021/ja411050r

(11) Long, Y. T.; Zhang, M. N. Sci. China Chem. 2009, 52, 731.

(12) Kan, C. X.; Wang, C. S.; Li, H. C.; Qi, J. S.; Zhu, J. J.; Li, Z. S.; Shi, D. N. Small 2010, 6, 1768. doi: 10.1002/smll.201000600

(13) Kan, C. X.; Zhu, J. J.; Zhu, X. G. Journal of Physics D-Applied Physics 2008, 41, 155304. doi: 10.1088/0022-3727/41/15/ 155304

(14) Murphy, C. J.; Thompson, L. B.; Chernak, D. J.; Yang, J. A.; Sivapalan, S. T.; Boulos, S. P.; Huang, J. Y.; Alkilany, A. M.; Sisco, P. N. Current Opinion in Colloid \& Interface Science 2011, 16, 128.

(15) Li, C. C.; Sun, L.; Sun, Y. Q.; Teranishi, T. Chem. Mater. 2013, 25, 2580. doi: 10.1021/cm400392e

(16) Millstone, J. E.; Hurst, S. J.; Metraux, G. S.; Cutler, J. I.; Mirkin, C. A. Small 2009, 5, 646. doi: 10.1002/smll.v5:6

(17) Dertli, E.; Coskun, S.; Esenturk, E. N. J. Mater. Res. 2013, 28, 250. doi: $10.1557 /$ jmr.2012.407

(18) Sinha, A. K.; Basu, M.; Sarkar, S.; Pradhan, M.; Pal, T. Langmuir 2010, 26, 17419. doi: 10.1021/la102387x

(19) Kim, J. U.; Cha, S. H.; Shin, K.; Jho, J. Y.; Lee, J. C. Adv. Mater 2004, 16, 459 .

(20) Wang, J. G.; Tian, M. L.; Mallouk, T. E.; Chan, M. H. W. J. Phys. Chem. B 2004, 108, 841. doi: 10.1021/jp035068q

(21) Forrer, P.; Schlottig, F.; Siegenthaler, H.; Textor, M. J. Appl. Electrochem. 2000, 30, 533. doi: 10.1023/A:1003941129560

(22) Wang, J. Faraday Discuss. 2013, 164, 9. doi: 10.1039/ c3fd00105a
(23) Li, Y.; Koshizaki, N.; Cai, W. P. Coord. Chem. Rev. 2011, 255, 357. doi: 10.1016/j.ccr.2010.09.015

(24) Dar, F. I.; Habouti, S.; Minch, R.; Dietze, M.; Es-Souni, M. J. Mater. Res. 2012, 22, 8671.

(25) Morita, C.; Tanuma, H.; Kawai, C; Ito, Y.; Imura, Y.; Kawai, T. Langmuir 2013, 29, 1669. doi: 10.1021/la304925e

(26) Mizoguchi, D.; Murouchi, M.; Hirata, H.; Takata, Y.; Niidome, Y.; Yamada, S. J. Nanopart. Res. 2011, 13, 6297. doi: 10.1007/ s11051-011-0555-0

(27) Kura, H.; Ogawa, T. J. Appl. Phys. 2010, 107, 074310. doi: $10.1063 / 1.3369441$

(28) Huo, Z. Y.; Tsung, C. K.; Huang, W. Y.; Zhang, X. F.; Yang, P. D. Nano Lett. 2008, 8, 2041. doi: 10.1021/n18013549

(29) Ohnishi, H.; Kondo, Y.; Takayanagi, K. Nature 1998, 395, 780. doi: $10.1038 / 27399$

(30) Kondo, Y.; Takayanagi, K. Science 2000, 289, 606. doi: 10.1126/ science.289.5479.606

(31) Pazos-Perez, N.; Baranov, D.; Irsen, S.; Hilgendorff, M.; LizMarzan, L. M.; Giersig, M. Langmuir 2008, 24, 9855. doi: $10.1021 / 1 \mathrm{a} 801675 \mathrm{~d}$

(32) Wang, C.; Hu, Y.; Lieber, C. M.; Sun, S. J. Am. Chem. Soc. 2008, 130, 8902. doi: 10.1021/ja803408f

(33) Oo, T. Z.; Mathews, N.; Xing, G. C.; Wu, B.; Xing, B. G.; Wong, L. H.; Sum, T. C.; Mhaisalkar, S. G. J. Phys. Chem. C 2012, 116, 6453. doi: 10.1021/jp2099637

(34) Pud, S.; Kisner, A.; Heggen, M.; Belaineh, D.; Temirov, R.; Simon, U.; Offenhausser, A.; Mourzina, Y.; Vitusevich, S. Small 2013, 9, 846. doi: 10.1002/smll.v9.6

(35) Yoshihira, M.; Moriyama, S.; Guerin, H.; Ochi, Y.; Kura, H.; Ogawa, T.; Sato, T.; Maki, H. Appl. Phys. Lett. 2013, 102, 203117-1. doi: 10.1063/1.4807806

(36) Wang, C.; Sun, S. H. Chem. Asian J. 2009, 4, 1028. doi: 10.1002/asia.v4:7

(37) Lu, Y.; Song, J.; Huang, J. Y.; Lou, J. Adv. Funct. Mater. 2011, 21, 3982. doi: 10.1002/adfm.v21.20

(38) Lu, W.; Lieber, C. M. Nat. Mater. 2007, 6, 841. doi: 10.1038/ nmat2028

(39) Feng, H.; Yang, Y.; You, Y.; Li, G.; Guo, J.; Yu, T.; Shen, Z.; Wu, T.; Xing, B. Chem. Commun. 2009, 1984.

(40) Lu, X. M.; Yavuz, M. S.; Tuan, H. Y.; Korgel, B. A.; Xia, Y. N. J. Am. Chem. Soc. 2008, 130, 8900. doi: 10.1021/ja803343m

(41) Huang, X.; Li, S.; Wu, S.; Huang, Y.; Boey, F.; Gan, C. L.; Zhang, H. Adv. Mater. 2012, 24, 979. doi: 10.1002/ adma.201104153

(42) He, J.; Wang, Y.; Feng, Y.; Qi, X.; Zeng, Z.; Liu, Q.; Teo, W. S.; Gan, C. L.; Zhang, H.; Chen, H. ACS Nano 2013, 7, 2733. doi: $10.1021 / \mathrm{nn} 4001885$ 